\title{
The management of bronchus intermedius complications after lung transplantation: A retrospective study
}

\author{
Shahrzad M Lari ${ }^{1 *}$, Francois Gonin ${ }^{2}$ and Arlette Colchen ${ }^{2}$
}

\begin{abstract}
Background: Airway complications following lung transplantation remain a significant cause of morbidity and mortality. The management of bronchial complications in Bronchus Intermedius (BI) is challenging due to the location of right upper bronchus. The aim of this study was to analyze the results of BI Montgomery T-tube stent in a consecutive patients with lung transplantations.

Methods: Between January 2007 and December 2010, 132 lung transplantations were performed at Foch Hospital, Suresnes, France. All the patients who had BI Montgomery T-tube after lung transplantation were included in this retrospective study. The demographic and interventional data and also complications were recorded.

Results: Out of 132 lung transplant recipients, 12 patients (9 male and 3 female) were entered into this study. The indications for lung transplantation were: cystic fibrosis 8 (67\%), emphysema $3(25 \%)$, and idiopathic pulmonary fibrosis 1 (8\%). Most of the patients (83\%) had bilateral lung transplantation. The mean interval between lung transplantation and interventional bronchoscopy was $11.5 \pm 9.8$ (SD) months. There was bronchial stenosis at the level of $\mathrm{Bl}$ in 7 patients (58.3\%). The Montgomery T-tube number 10 was used in 9 patients (75\%). There was statistically significant difference in Forced Expiratory Volume in one second (FEV1) before and after stent placement $(p=0.01)$. The most common complication after stent placement was migration (33\%).

Conclusion: Bl complications after lung transplantation are still a significant problem. Stenosis or malacia following lung transplantation could be well managed with modified Montgomery T-tube.
\end{abstract}

\section{Background}

Airway complications are still a potential cause of morbidity and mortality after lung transplantation even with the considerable improvements in anastomotic techniques and immunosuppressive drugs [1,2]. The reported incidence of airway complications is about 7 to $18 \%$ with a mortality rate of 2 to $4 \%$ [3].

Since systemic arterial blood flow is not preserved during engraftment, lung transplantation is completely different from other transplantations [4]. Revascularization of the bronchial arterial flow may take up to 4 weeks $[3,5]$. Thus the viability of donor's bronchus is completely dependent to the retrograde collaterals from low pressure pulmonary circulation $[3,6]$. During this period, the

\footnotetext{
* Correspondence: larish@mums.ac.ir

'Lung disease and Tuberculosis Research Center, School of Medicine,

Mashhad University of Medical Sciences, Mashhad, Iran

Full list of author information is available at the end of the article
}

anastomotic site is prone to ischemia and may develop varying degrees of necrosis and dehiscence [7]. Therefore airway complications have been mainly attributed to ischemia of donor bronchus during the immediate post transplant period $[3,8]$. Other attributing factors like primary graft dysfunction [9], pre and post pulmonary infection $[3,10]$, rejection [4], intense immunosupression [4], and prolonged mechanical ventilation [11] are associated with increased risk of anastomotic airway complications.

The clinical presentation of airway complications varies from focal infection, necrosis, dehiscence, and granulation tissue formation to stenosis and malacia [7].

The Bronchus Intermedius (BI) is especially prone to ischemia after lung transplantation [7]. Different therapeutic modalities, like endobronchial dilatation, laser, cryosurgery, and endobronchial stents, are used for the treatment of BI stenosis depending on the severity of stenosis. The main problem with stent placement in $\mathrm{BI}$ is the possible

\section{Biomed Central}

(c) 2012 Lari et al; licensee BioMed Central Ltd. This is an Open Access article distributed under the terms of the Creative Commons Attribution License (http://creativecommons.org/licenses/by/2.0), which permits unrestricted use, distribution, and reproduction in any medium, provided the original work is properly cited. 
obstruction of right upper lobe orifice [7] or restenosis at the upper part of the stent. In Foch Hospital, the modified Montgomery T-tube (Novatech, France) as shown in Figure 1 was applied as stent for BI stenosis or malacia. In this technique, after measuring, cutting, and manual smoothening the distal ends, the tracheotomy arm of the $\mathrm{T}$ tube is placed in the upper lobe bronchus to maintain its patency.

The purpose of this study was to analyze the results of the modified Montgomery T-tube in BI of lung transplant patients over the past 4 years.

\section{Materials and methods}

We reviewed the data of all the lung transplantations which were performed in the Lung Transplantation and Thoracic Surgery department of Foch Hospital, Suresnes, France between January 2007 and December 2010. All the patients with Montgomery T-Tube in BI location were entered into this retrospective study.

Heart lung, bilateral lung, and single lung transplantation were performed according to the standard methods $[2,12]$. End-to-end anastomosis with no revascularization techniques had been applied.

All of the patients received triple immunosuppressive therapy consisting of cyclosporine, azathioprine or mycophenolate mofetil, and prednisone. Also chemoprophylaxis against pneumocystis jiroveci, and cytomegalovirus were given to the patients.

Surveillance bronchoscopy and transbronchial lung biopsy were performed immediately after transplantation and subsequently on postoperative day 7 , month $1,2,3$, $6,9,12,18$, and 24 .
The severity of bronchial ischemia at the level of anastomosis was assessed as following:

0 : No ischemia.

1: Mild ischemia (one isolated ischemic patch or one at the level of anastomosis)

2: Moderate ischemia (circumferential anastomotic ischemia)

3: Severe ischemia (circumferential anastomotic ischemia and ischemia in segmental bronchi with or without dehiscence)

In the case of airway complications including stenosis, malacia, or obstructive necrotic tissues, rigid bronchoscopy (KARL STORZ, Germany) was applied. It was performed under general anesthesia and jet ventilation. Depending on the pathological finding, the suitable interventions including mechanical dilatation, laser, and cryotherapy were performed. The dilatation was used when there was a significant decline in forced expiratory volume in one second (FEV1) with no other etiology or narrowing of the airway $>50 \%$ of predicted diameter. Additionally, the Montgomery T-tube with appropriate size was inserted when there was significant stenosis or malacia (Figure 2, 3) but not necessarily after the first dilatation.

Spirometry was performed within 1 month intervals and also before and after any bronchial interventions when it was possible.

\section{Statistical analysis}

The data were analyzed using the Statistical Package for Social Sciences (Version 14.0; SPSS

Inc., Chicago, IL). The variables are presented as percentages and means \pm standard deviations. Descriptive
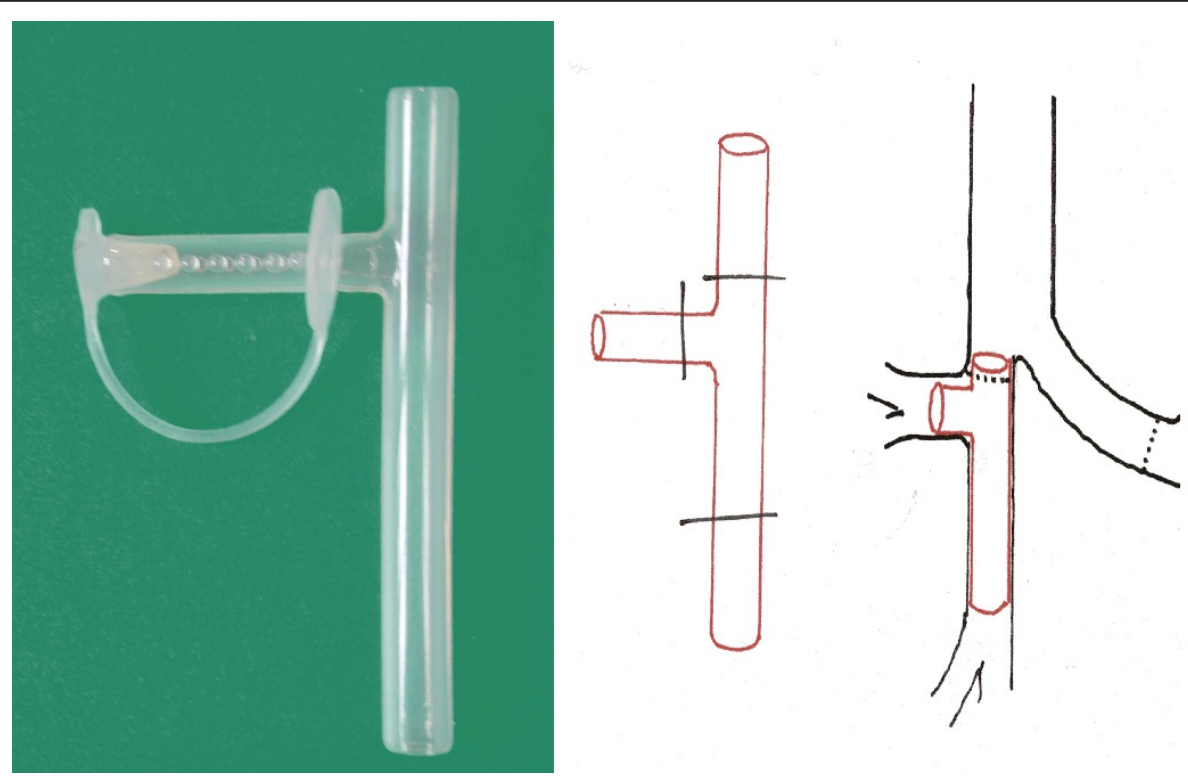

Figure 1 Montgomery T-tube placement in Bronchus Intermedius (BI) position. 

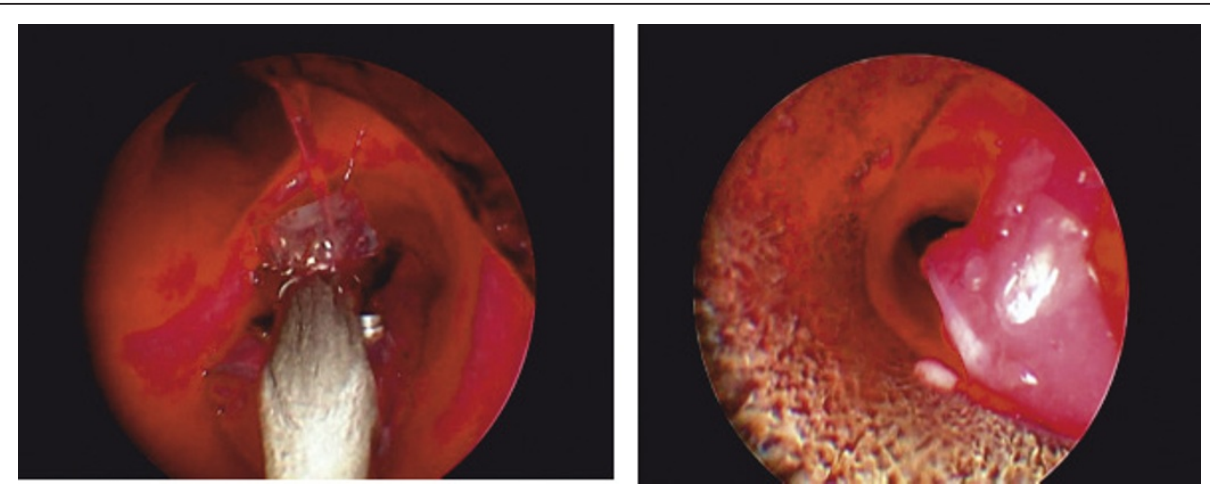

Figure 2 Introduction of T-tube in right main bronchus.

statistics were used to summarize the demographic characteristics of the patients. For comparison of the variables $T$-test was applied. $P$ values less than 0.05 were considered significant.

\section{Results}

Out of 132 lung transplantations, 12 patients (male/ female: 9/3) with mean age of $37 \pm 13.89$ years were enrolled into our study. The indications for lung transplantation were: cystic fibrosis 8 (67\%), emphysema 3 (25\%), and idiopathic pulmonary fibrosis 1 (8\%). Most of the patients $(10 / 12)$ had bilateral lung transplantation. The frequency of severe bronchial ischemia in one month after transplantation was $41.5 \%$ in comparison of
$8 \%$ in 7 days after operation $(p=0.03)$. The main clinical data of the patients are shown in Table 1.

There was bronchial stenosis at the level of BI in 7 patients (58.3\%). The Montgomery T-tube was placed in all of the patients. Out of 12 patients, $3(25 \%)$ had the size of 12 and others (75\%) size 10. The left side stent was placed in $3(25 \%)$ patients.

The data about rigid bronchoscopy are shown in Table 2. The mean total times of $7.4 \pm 2.6$ rigid bronchoscopy were performed in patients. There was statistically significant difference between the mean FEV1 before and after the stent placement (1762 \pm 586.70 and $2351 \pm 681.34$ respectively, $\mathrm{p}=0.01$ ) Figure 4.

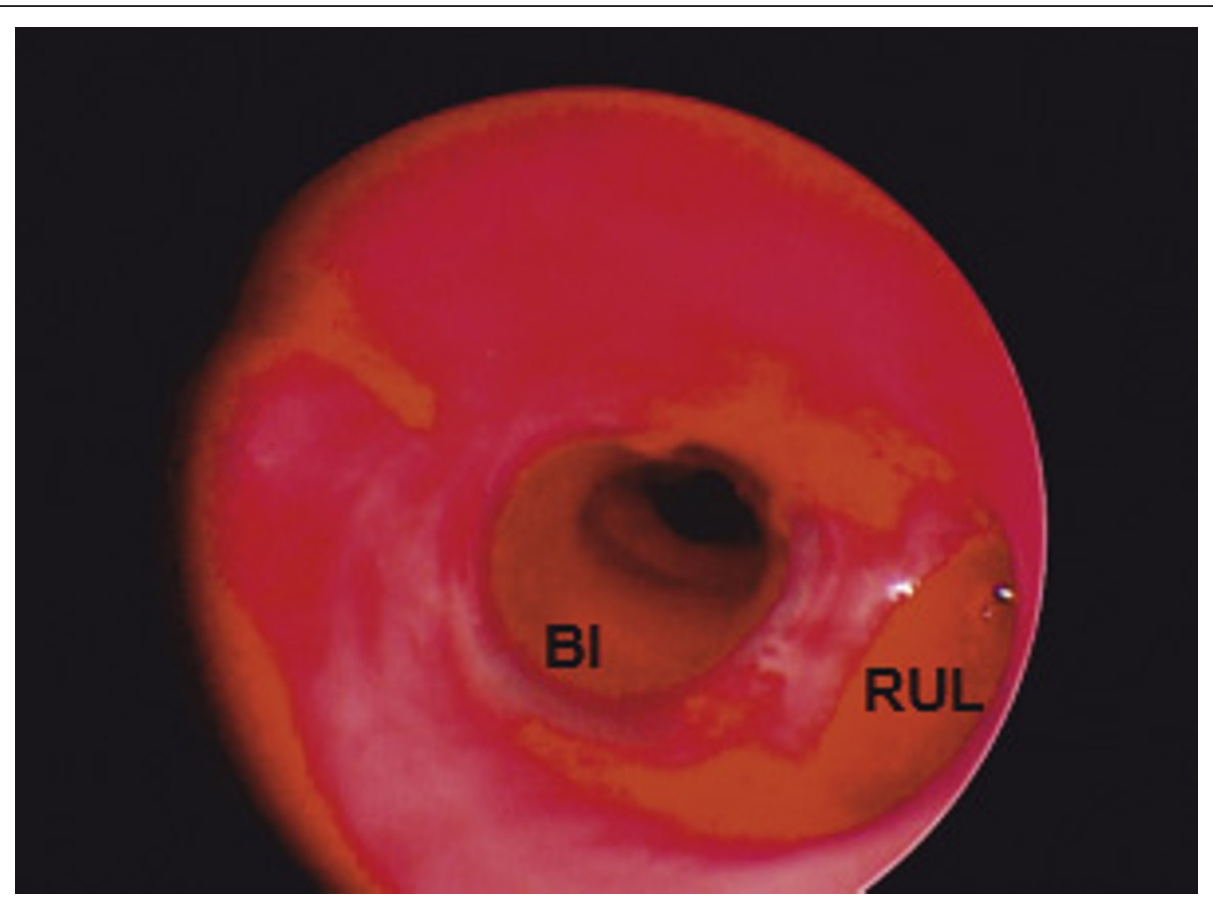

Figure 3 T-tube in bronchus intermedius (BI) and right upper lobe (RUL). 
Table 1 The demographic and transplantation parameters of the patients

\begin{tabular}{ll}
\hline $\begin{array}{l}\text { Clinical and interventional } \\
\text { parameters }\end{array}$ & Values \\
\hline Age & $37 \pm 13.89^{*}$ \\
\hline Etiology & $\begin{array}{l}\text { Cystic fibrosis:8 (67\%) } \\
\text { Emphysema:3 (25\%) } \\
\text { Idiopathic Pulmonary Fibrosis:1 } \\
(8 \%)\end{array}$ \\
\hline Type of transplantation & Bilateral: 9 (75\%) \\
& Bilateral+Kidney: 1 (8\%) \\
& Single lung (right): 2 (17\%) \\
\hline Ischemic time (hours) & Right: 4.7 $\pm 0.98^{*}$ \\
& Left: 3.9 $\pm 2.28^{*}$ \\
\hline Bronchial ischemia (7 ${ }^{\text {th }}$ day) & Grade 0:0 \\
& Grade 1:2 (17\%) \\
& Grade 2: $9(75 \%)$ \\
\hline Bronchial ischemia (1 & Grade 3:1(8\%) \\
& Grade 0:0 \\
& Grade 1:2 (17\%) \\
& Grade 2: $5(41.5 \%)$ \\
\hline
\end{tabular}

*The data are shown as mean \pm SD.

The minimum duration of follow up was 6 months. The most common complication after stent placement was migration of the stent (33\%). The Montgomery Ttube was extracted in 9 patients (75\%). Seven patients (58.3\%) needed a new stent.

\section{Discussion}

Despite the progressions of surgical methods in lung transplantation during recent years, airway complications are still a major concern in this field. The airway complications after lung transplantation can be divided in two phase: the early phase (during the first month after transplantation) including anastomotic infection, necrosis, or dehiscence which is mainly due to bronchial ischemia and the late phase including excess granulation tissue, bronchomalacia, and airway stenosis [3,7].

As we mentioned earlier, the main mechanism of bronchial ischemia is the interruption of bronchial blood flow after anastomosis [6,13]. Bronchial stenosis is the most common airway complication and often occurs in patients who have experienced anastomotic necrosis, dehiscence, or infection $[3,14]$. In our study, overall 10 patients (84\%) had significant stenosis.

During recent decades, many surgical methods have been proposed for preventing of bronchial ischemia $[3,15]$, but only end-to-end anastomosis is the recommended technique for it [3]. In our study, all of the lung transplantation was performed with end-to-end anastomosis method.

Since bronchial ischemia is a main underlying factor in occurrence of airway complications, assessment of the severity of ischemia seems to be necessary. We designed a classification staging according to the severity of ischemia on bronchoscopy. In our study 10 patients (83\%) had moderate to severe bronchial ischemia one month after transplantation. The comparison of bronchial ischemia in day 7 and month 1 after transplantation showed the progressive nature of ischemia.

It is well documented that most airway complications after lung transplantation occur at the anastomotic site but sometimes nonanastomotic bronchial stenosis may also occur [16]. Although the exact pathogenesis of this type of stenosis is not clear, but alloreactive injury, ischemic damage, and infection may concern [16]. Several cases of bronchial stenosis distal to the anastomotic site in the BI have been reported [17]. In our study, 59\% of bronchial stenosis was in BI without involvement of anastomosis. This type of stenosis is known as the vanishing bronchus intermedius syndrome that may be detected as late as 12 months post transplant $[7,17]$.

Table 2 The data of interventional bronchoscopy in patients

\begin{tabular}{ll}
\hline Variable & Value \\
\hline Indication & Stenosis:8 (66\%) \\
& Malacia: 2 (17\%) \\
\hline Location of stenosis & Stenosis+ Malacia: 2 (17\%) \\
& Anastomosis: 4 (33\%) \\
& Bronchus Intermedius (Bl): 7(59\%) \\
\hline Interval between transplantation and intervention (months) & Anastomosis + Bl: 1(8\%) \\
\hline Duration of stent replacement (months) & $11.5 \pm 9.8^{*}$ \\
\hline Complications & $6 \pm 6.6^{*}$ \\
& Migration: 4(33\%) \\
& Stenosis: 3(25\%) \\
\hline FEV1 (ml) & Obstruction:2(17\%) \\
& Infection: 1(8\%) \\
& No complications:2(17\%) \\
\hline
\end{tabular}

\footnotetext{
*The data are shown as mean \pm SD.
} 


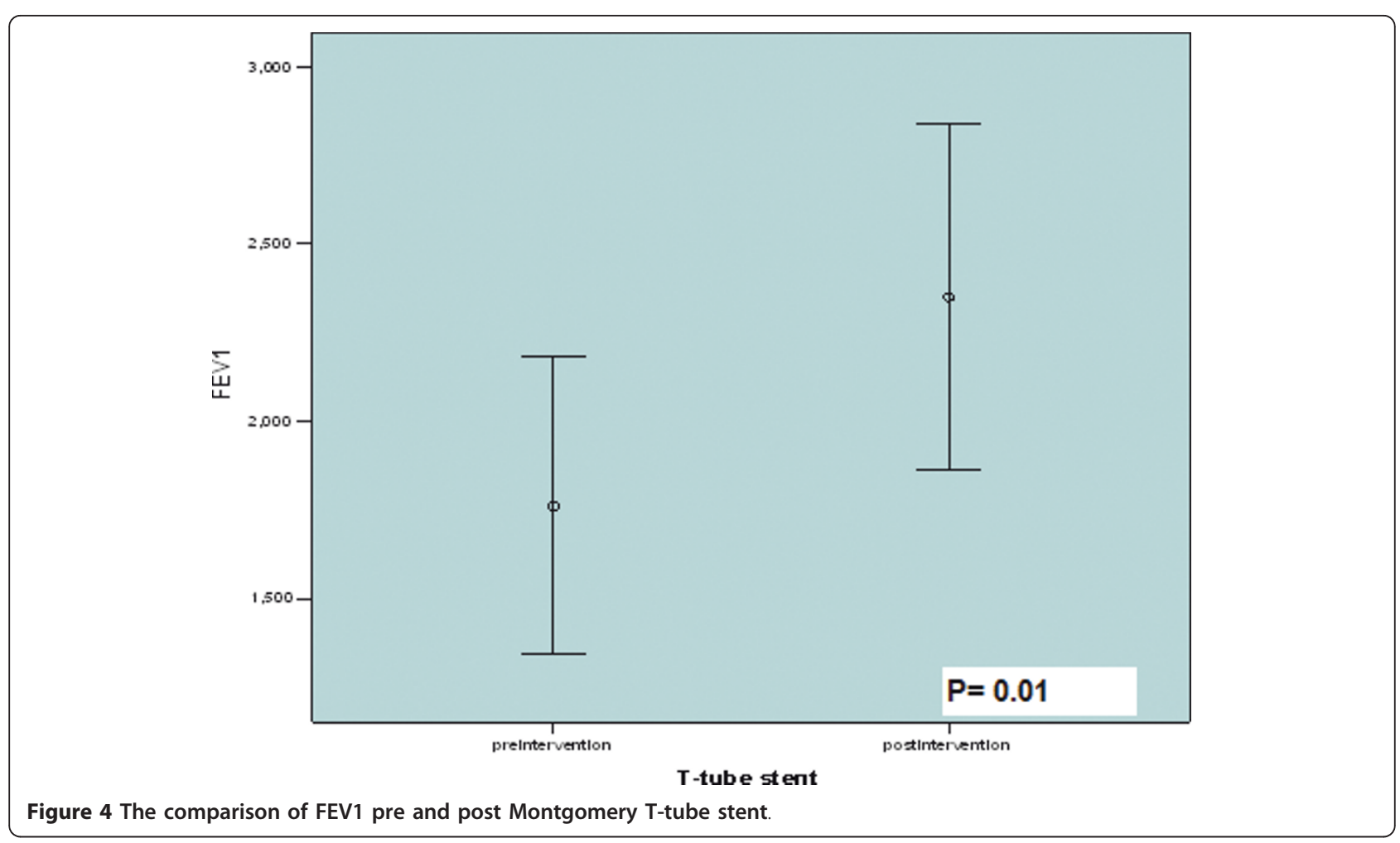

The mean interval between transplantation and stent placement was 11.5 months in this study.

Management of the bronchial stenosis depends on severity of narrowing. Different modalities like mechanical dilatation, laser, cryotherapy, and stent are applied in appropriate indications [18]. In the case of nonanastomotic bronchial stenosis, the therapeutic options are not different. But it is necessary to keep a stent in the correct position without occlusion of the right upper lobe bronchus. We used modified Montgomery T-tube as shown in Figure 1, 2, and 3. By this method, the right upper bronchus will be kept open.

In our study, the most common complication was migration. If we could use an appropriate diameter Ttube stent which is fit to the $\mathrm{BI}$, the complication may be lowered. The special designed T-tube stents suitable for $\mathrm{BI}$ in diameter may lower the risk of complications like migration.

\section{Conclusions}

Airway complications after lung transplantation are still a managing problem; especially when they are located in BI. For maintaining the patency of BI, especial stents are required because of the position of right upper bronchus. We used modified Montgomery T-tube for this purpose. But due to complications like migration, especially designed stents compatible with diameter of $\mathrm{BI}$ and main bronchus are nowadays applied. So we expect that the efficiency of this endoscopic procedure will be increased because there is no real efficient treatment of this type of post lung transplantation bronchial complication.

\section{List of abbreviations}

BI: Bronchus Intermedius; FEV1: Forced Expiratory Volume in one second

\section{Author details}

${ }^{1}$ Lung disease and Tuberculosis Research Center, School of Medicine, Mashhad University of Medical Sciences, Mashhad, Iran. ${ }^{2}$ Interventional bronchoscopy unit, Thoracic Surgery and lung transplantation department, Foch hospital, Suresnes, France.

\section{Authors' contributions}

$A C$ and FG participated in performing the procedure of stent placement and management of the patients. FG also participated in design of the study. SML participated in design of the study, statistical analysis, and draft the manuscript. All the authors read and approved the manuscript.

\section{Competing interests}

The authors declare that they have no competing interests.

Received: 23 September 2011 Accepted: 20 January 2012

Published: 20 January 2012

\section{References}

1. Moreno P, Alvarez A, Alger FJ, Cano JR, Espinosa D, Cerezo F, Baamonde C, Salvatierra A: Incidence, management and clinical outcomes of patients with airway complications following lung transplantation. European Journal of Cardiothoracic surgery 2008, 34:1198-1205.

2. Chhajed PN, Malouf MA, Tamm M, Spratt P, Glanville R: Interventional bronchoscopy for the management of airway complications following lung transplantation. Chest 2001, 120:1894-1899. 
3. Santacruz JF, Mehta AC: Airway complications and management after lung transplantation. Proceedings of the American thoracic society 2009, 6:79-83.

4. Weder W, Inci I, Korom S, Kestenholz P, Hillinger S, Eich C, Irani S, Lardinois D: Airway complications after lung transplantation: risk factors, prevention and outcome. European Journal of Cardiothoracic surgery 2009, 35:293-298.

5. De Wauwer CV, Raemdonck DV, Verleden GM, Dupont L, De Leyn P, Coosemans W, Nafteux P, Lerut T: e Risk factors for airway complications within the first year after lung transplantation. European Journal of Cardiothoracic surgery 2007, 31:703-710.

6. Ramirez J, Patterson GA: Airway complications after lung transplanatation. Semin Thorac Cardiovasc Surg 1992, 4:147-53.

7. Cypel M, Waddell T, Keshavjee S: Airway complications after lung transplantation.up to date 19.1.

8. Mulligan MS: Endoscopic management of airway complications after lung transplantation. Chest Surg Clin N Am 2001, 11:907-915.

9. Ruttmann E, Ulmer H, Marchese M, Dunst K, Geltner C, Margreiter R, Laufer G, Mueller LC: Evaluation of factors damaging the bronchial wall in lung transplantation. J Heart Lung Transplant 2005, 24:275.

10. Herrera JM, McNeil KD, Higgins RS, Coulden RA, Flower CD, Nashef SA, Wallwork J: Airway complications after lung transplantation: treatment and long-term outcome. Ann Thorac Surg 2001, 71:989.

11. Alvarez A, Algar J, Santos F, Lama R, Aranda JL, Baamonde C, Lopez-Pujol J, Salvatierra A: Airway complications after lung transplantation: a review of 151 anastomoses. Eur J Cardiothorac Surg 2001, 19:381.

12. Pasque MK, Cooper JD, Kaiser LR, Haydock DA: Improved technique for bilateral lung transplantation: rationale and initial clinical experience. Am ThoracSurg 1990, 49:758-791.

13. Shennib H, Massard G: Airway complications in lung transplantation. Ann Thorac Surg 1994, 57:506-511.

14. Herrera JM, McNeil KD, Higgins RS, Coulden RA, Flower CD, Nashef SA, Wallwork J: Airway complications after lung transplantation:treatment and long-term outcome. Ann Thorac Surg 2001, 71:989-993.

15. Gafein ES, McGregor CC, Galantowicz ME, Schuman LL: Deleterious effects of telescoped bronchial anastomosis in single and bilateral lung transplantation. Ann Transplant 2000, 5:5-11.

16. Hasegawa T, lacono AT, Orons PD, Yousem SA: Segmental nonanastomotic bronchial stenosis after lung transplantation. Ann Thorac Surg 2000, 69:1020.

17. Kshettry VR, Kroshus TJ, Hertz MI, Hunter DW, Shumway SJ, Morton Bolman R III: Early and late airway complications after lung transplantation: incidence and management. Ann Thorac Surg 1997, 63:1576-83.

18. Paulson EC, Singhal S, Kucharczuk JC, Kucharczuk JC, Sterman DH, Kaiser LR, Marshall MB: Bronchial sleeve resection for post transplant stricture. Ann Thorac Surg 2003, 76:2075-2076.

doi:10.1186/1749-8090-7-8

Cite this article as: Lari et al:: The management of bronchus intermedius complications after lung transplantation: A retrospective study. Journal of Cardiothoracic Surgery 2012 7:8.

\section{Submit your next manuscript to BioMed Central and take full advantage of:}

- Convenient online submission

- Thorough peer review

- No space constraints or color figure charges

- Immediate publication on acceptance

- Inclusion in PubMed, CAS, Scopus and Google Scholar

- Research which is freely available for redistribution

Submit your manuscript at www.biomedcentral.com/submit
Biomed Central 